\title{
The incorporation in vitro of sulphate ions into synaptic-membrane glycoproteins
}

\author{
Christopher J. Branford WHITE \\ Department of Biology, Oxford Polytechnic, Oxford OX3 OBP, U.K.
}

(Received 8 June 1981/Accepted 6 August 1981)

\begin{abstract}
Synaptosomes from sheep brain cortex were incubated with carrier-free $\mathrm{Na}_{2}{ }^{35} \mathrm{SO}_{4}$ and the synaptic plasma membranes were isolated. The membranes were free of contamination from cytosol, mitochondria and microsomal material and accounted for $30 \%$ of the radioactivity present in the synaptosomal particulate fraction. Control experiments demonstrated that the radioactivity present in the preparation was not due to non-specific binding of sulphate ions. The synaptic membranes contained at least six ${ }^{35}$ S-containing protein bands with molecular weights between 160000 and 16000 . Analysis showed that the radioactivity was located in the carbohydrate moiety of a glycopeptide.
\end{abstract}

Sulphate-containing glycoproteins have been located in rat brain nuclei, myelin of the central and peripheral nervous systems and synaptic membranes (Mattieu et al., 1975a,b; Margolis et al., 1976; Simpson et al., 1976). Structural studies on sulphated glycopeptides released after proteolytic treatment have suggested that the sulphate group exists as an ester linkage to the oligosaccharide chain (Katzman, 1972). Furthermore there is little variation in the carbohydrate composition of certain sulphated and non-sulphated glycopeptide fractions (Brunngraber et al., 1973).

Recent findings in this laboratory have shown that synaptosomes are capable of incorporating inorganic sulphate without the need for an endogenous energy source. This process is dependent on time, temperature and substrate concentration (White, 1979a). A similar study has also shown that the sulphate group is incorporated into a number of synaptosomal glycoproteins (White, 1980). These results, however, did not demonstrate the precise location of the ${ }^{35} \mathrm{~S}$-containing proteins within the synaptic preparation. The findings presented in this report suggest that inorganic sulphate can be incorporated into a range of glycoproteins associated with synaptic plasma membranes.

\section{Material and methods}

\section{Isolation of subcellular fractions}

Sheep brain cortex was homogenized in $0.32 \mathrm{M}$ sucrose containing $5 \mathrm{~mm}$-sodium phosphate, $\mathrm{pH} 7.4$, and $0.1 \mathrm{~mm}$-EDTA. The crude mitochondrial fraction $(10000 \mathrm{~g}$ pellet) was washed three times to reduce microsomal contamination and synaptosomes were prepared by using a Ficoll/sucrose discontinuous density gradient (Cotman \& Matthews, 1971). Excess Ficoll was removed by washing the preparation with buffered sucrose and centrifugation at $45000 \mathrm{~g}$. Synaptosomes were lysed by suspending in $20 \mathrm{vol}$. of $6 \mathrm{~mm}$-Tris $/ \mathrm{HCl}, \mathrm{pH} 8.2$, and the crude synaptic membranes were collected by centrifugation at $60000 \mathrm{~g}$. Synaptic plasma membranes were isolated as described by Gurd et al. (1974).

Myelin was prepared from whole cortical homogenate after three hypo-osmotic shock stages before sucrose-density-gradient centrifugation (Norton \& Poduslo, 1973). Brain mitochondria were isolated from the pellet obtained from the Ficoll/sucrose centrifugation (Cotman \& Matthews, 1971) and the microsomal fraction was isolated from the $10000 \mathrm{~g}$ supernatant (Gurd et al., 1974).

\section{Incubation with $\mathrm{Na}_{2}{ }^{35} \mathrm{SO}_{4}$}

Sucrose-washed brain mitochondria, synaptosomes and the microsomal fraction were suspended in $10 \mathrm{~mm}-\mathrm{Tris} / \mathrm{HCl}(\mathrm{pH} 7.4)$, containing $15 \mathrm{mM}$ $\mathrm{MgCl}_{2}, 146 \mathrm{~mm}-\mathrm{NaCl}$ and $4 \mathrm{mM}-\mathrm{KCl}$, and incubated with $\mathrm{Na}_{2}{ }^{35} \mathrm{SO}_{4}(5 \mu \mathrm{Ci} / \mathrm{mg}$ of protein; The Radiochemical Centre, Amersham, Bucks., U.K.) for $30 \mathrm{~min}$ at $25^{\circ} \mathrm{C}$. In some experiments the incubation medium contained $100 \mathrm{~mm}$-sucrose. Before the addition of the radioactive precursor the subcellular preparations were pre-incubated in media for $15 \mathrm{~min}$. The uptake of ${ }^{35} \mathrm{~S}$ was terminated by transfer to unlabelled medium $\left(4^{\circ} \mathrm{C}\right)$ and excess radioactivity 
was removed by repeated washing with $0.32 \mathrm{M}$ sucrose.

\section{Isolation and desulphation of ${ }^{35} S$-containing glyco- peptides}

Synaptic plasma membranes were defatted by extraction with chloroform/methanol $(2: 1, \mathrm{v} / \mathrm{v})$. Free glycopeptides/glycosaminoglycans were released by papain hydrolysis and glycosaminoglycans were selectively precipitated with $1 \%$ cetylpyridinium chloride (White, 1978). The supernatant was chromatographed on a DEAE-cellulose column (DE-52; Whatman) that had been previously equilibrated in $50 \mathrm{~mm}$-sodium phosphate $(\mathrm{pH} 7.0)$ at $25 \mathrm{ml} / \mathrm{h}$. The column was eluted with a linear $\mathrm{NaCl}$ gradient $(0-0.4 \mathrm{M})$. The ${ }^{35} \mathrm{~S}$-containing fractions were further chromatographed on Sephadex G-50; the flow rate was adjusted to $10 \mathrm{ml} / \mathrm{h}$. The glycopeptide isolated from the synaptic-plasma-membrane preparation was completely desulphated by hydrolysis in $6 \mathrm{M}-\mathrm{HCl}$ at $100^{\circ} \mathrm{C}$ for $20 \mathrm{~h}$. The inorganic sulphate released was precipitated with $0.1 \mathrm{M}-\mathrm{BaCl}_{2}$ after the addition of carrier, unlabelled $0.2 \mathrm{M}^{-}$ $\mathrm{Na}_{2} \mathrm{SO}_{4}$. After centrifugation $(2000 \mathrm{~g})$ both the supernatant and the pellet were counted for radioactivity in an Isocap/300 (Nuclear Chicago) scintillation counter.

\section{Sodium dodecyl sulphate/polyacrylamide-gel electrophoresis}

Membrane samples were solubilized in 2\% sodium dodecyl sulphate, $8 \mathrm{M}$-urea and $1 \% 2$-mercaptoethanol/0.5 mM-EDTA in $0.1 \mathrm{M}$-sodium phosphate (pH 7.4) and electrophoresed on $7.5 \%$ polyacrylamide gels containing a 5\% stacking gel. Gels were washed in $12 \%$ trichloroacetic acid/propan-1-ol $(72: 25, \mathrm{v} / \mathrm{v})$ and then stained in $0.04 \%$ Coomassie Blue. All samples were compared against standard molecular markers (BDH). Unstained gels were sliced $(1.5 \mathrm{~mm})$ and solubilized in $40 \% \mathrm{H}_{2} \mathrm{O}_{2}$ before counting for radioactivity.

\section{Chemical and enzymic procedures}

$\left(\mathrm{Na}^{+}+\mathrm{K}^{+}\right)$-dependent ATPase (EC 3.6.1.3), succinate dehydrogenase (EC 1.3.99.1), acetylcholinesterase (EC 3.1.1.7) and neutral $\alpha$-Dglucosidase (EC 3.2.1.20) activities were determined as described previously (Ellman et al., 1961; Earl \& Korner, 1965; Verity, 1972; Peters et al., 1980). Samples for lactate dehydrogenase (EC 1.1.1.27) were assayed in the presence of $0.05 \%$ Triton X-100 (Johnson, 1960). RNA, sialic acid and neutral carbohydrates were determined colorimetrically (Fleck \& Begg, 1965; Jourdian et al., 1970; Brunngraber et al., 1973). Amino sugars and amino acids were analysed on a Joel JLC 6AH amino acid autoanalyser (White, 1979b). Protein concen- trations were estimated by the modified Lowry method (Markwell et al., 1978).

Myelin basic protein was specifically determined by using an enzyme-linked immunosorbent assay system; samples were pretreated with $0.2 \mathrm{M}$-sodium citrate, $\mathrm{pH} 3.7$, to remove contaminating material (Groome, 1980).

\section{Results}

The degree of purity exhibited by the synaptic material sedimenting at the $7.5-13 \%$ Ficoll layer was assessed using the plasma- and synapticmembrane markers $\left(\mathrm{Na}^{+}+\mathrm{K}^{+}\right)$-dependent ATPase and acetylcholinesterase. Moreover electron micrographs (not shown here) of the washed synaptosomal fraction demonstrated that at least $60 \%$ of this preparation was synaptosomal in origin. Within the preparation extrasynaptosomal mitochondria and myelin accounted for no more than $20-30 \%$, as indicated by using specific enzymic and chemical markers for these subcellular components (Table 1). A 2.5- and 4-fold increase in $\left(\mathrm{Na}^{+}+\mathrm{K}^{+}\right)$-dependent ATPase and acetylcholinesterase activity of the synaptic-plasma-membrane material collected from the $0.6 \mathrm{M}-/ 0.8 \mathrm{M}$-sucrose interface was obtained. The purified membrane fraction was found to be free of material associated with the cytosol, mitochondria, myelin and the microsomal fraction (Table 1), and accounted for $43 \%$ of the protein applied to the discontinuous sucrose gradient.

After pre-incubation, carrier-free $\mathrm{Na}_{2}{ }^{35} \mathrm{SO}_{4}$ was added to the synaptosomal suspension. After removal of excess radioactivity the specific radioactivity values reported (Table 1 ) indicate that approx. $0.4 \%$ of the radioactive label added to the original incubation medium was incorporated into the crude membrane fraction. Moreover a similar radioactivity value was obtained when synaptosomes were incubated in a medium that included sucrose. The purified plasma membranes contained $30 \%$ of the ${ }^{35} \mathrm{~S}$ present in the unfractionated membrane sample applied to the density gradient. The remaining radioactivity was detected in material that sedimented to more dense regions in the sucrose gradient. Approx. $60 \%$ of the ${ }^{35} \mathrm{~S}$ was located in the pellet, which was also enriched with succinate dehydrogenase activity (specific activity 3.2 units/ $\mathrm{mg}$ of protein). No radioactive precursor was detected in either of the synaptosomal soluble or crude membrane fractions after synaptosomes had been heat-treated $\left(80^{\circ} \mathrm{C}\right.$ for $\left.10 \mathrm{~min}\right)$ before the addition of $\mathrm{Na}_{2}{ }^{35} \mathrm{SO}_{4}$. Furthermore no decrease in ${ }^{35} \mathrm{~S}$ was noted when these membranes were washed with $0.2 \mathrm{M}-\mathrm{Na}_{2} \mathrm{SO}_{4}$. It is unlikely therefore that the ${ }^{35} \mathrm{~S}$ present in the synaptic-plasma-membrane fraction had resulted through non-specific binding of the radioactive precursor. 
Table 1. Distribution of ${ }^{35} \mathrm{~S}$ in synaptic fractions and assessment of subcellular fraction for contamination using positive and negative markers

The results represent the average of four experiments taken in triplicate \pm S.E. Enzyme values are expressed as $\mu$ mol of substrate utilized/h per mg of protein and RNA as $\mu \mathrm{g} / \mathrm{mg}$ of protein. Abbreviation used: ND, not detected.

\begin{tabular}{|c|c|c|c|c|c|}
\hline & $\begin{array}{c}\text { Total } \\
\text { homogenate }\end{array}$ & Synaptosomes & $\begin{array}{c}\text { Crude synaptic } \\
\text { membranes }\end{array}$ & $\begin{array}{c}\text { Synaptic plasma } \\
\text { membranes }\end{array}$ & Maximum values \\
\hline $\begin{array}{l}\left(\mathrm{Na}^{+}+\mathrm{K}^{+}\right) \text {-dependent } \\
\text { ATPase }\end{array}$ & $10.7 \pm 1.4$ & $58 \pm 5.2$ & $72 \pm 6.9$ & $185 \pm 19.2$ & \\
\hline Acetylcholinesterase & 一 & $2.1 \pm 0.2$ & $2.4 \pm 0.22$ & $9.0 \pm 0.91$ & \\
\hline Succinate dehydrogenase & $1.2 \pm 0.11$ & $0.8 \pm 0.09$ & $1.0 \pm 0.07$ & ND & Mitochondria $(3.0 \pm 0.28)$ \\
\hline Neutral $\alpha$-D-glucosidase & $2.8 \pm 0.3$ & $1.8 \pm 0.21$ & $0.8 \pm 0.06$ & ND & Microsomes $(36 \pm 4.1)$ \\
\hline Lactate dehydrogenase & $48 \pm 3.2$ & $63 \pm 4.8$ & ND & ND & Cytosol $(168 \pm 14.2)$ \\
\hline RNA & $14 \pm 1.7$ & - & $15 \pm 1.8$ & & Microsomes $(94 \pm 8.2)$ \\
\hline $\begin{array}{l}\text { Myelin basic protein } \\
\text { (\% of total protein) }\end{array}$ & $2.9 \pm 0.3$ & $6.9 \pm 0.71$ & $1.2 \pm 0.8$ & ND & Myelin $(27.8 \pm 3.1)$ \\
\hline $\begin{array}{l}\text { Specific radioactivity } \\
\text { (d.p.m./mg of protein) }\end{array}$ & & & $50000 \pm 2500$ & $15000 \pm 800$ & \\
\hline
\end{tabular}

Freeze-dried synaptic plasma membranes were extracted with chloroform/methanol and the solubilized lipid represented $28 \%$ of the ${ }^{35} \mathrm{~S}$ present in the membrane preparation. No sulphatecontaining protein was detected in the organic solvent extracts after papain treatment, DEAEcellulose and gel filtration using a Sephadex G-50 column (White, 1980). Samples of lipid-free plasma

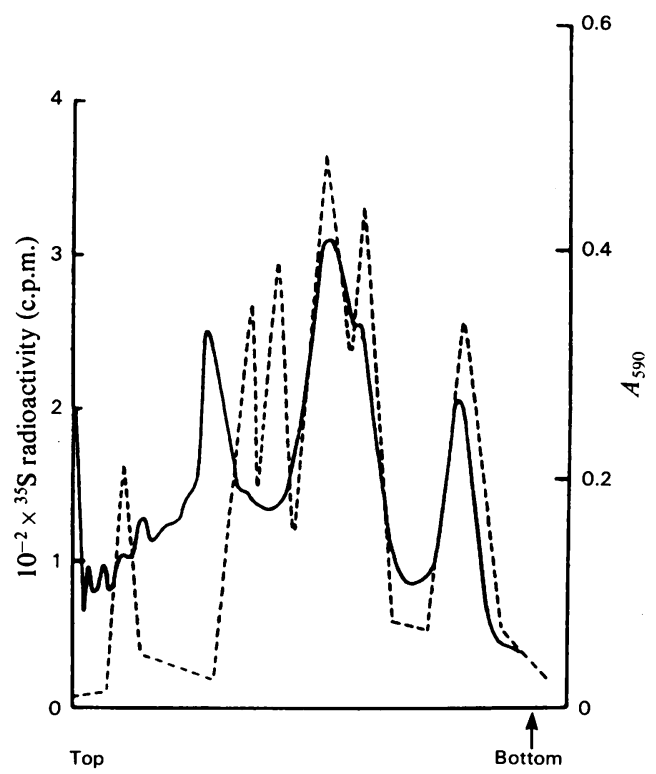

Fig. 1. Sodium dodecyl sulphate/polyacrylamide-gel electrophoresis

Samples $(30 \mu \mathrm{g}$ of protein) were run at $4 \mathrm{~mA}$ per tube with Bromophenol Blue as a tracking dye. Gels were stained for protein $\left(-; A_{590}\right)$ and counted for ${ }^{35} \mathrm{~S}$ radioactivity (----). membrane were then solubilized in sodium dodecyl sulphate/urea and dialysed against tank buffer; no ${ }^{35} \mathrm{~S}$ was present in the diffusate. The electrophoretic scan pattern of the plasma-membrane proteins on $7.5 \%$ polyacrylamide gels is shown in Fig. 1. At least 11 Coomassie Blue-staining bands were observed with mol.wts. 160000-16000. Transverse slicing of unstained gels revealed that radioactivity was located in six of the protein bands $(160000$, $140000,124000,70000,27000$ and 16000). Gels were also stained for carbohydrate-containing material using the Schiff/periodate reaction. Although rather diffuse, all the positively stained bands did correspond to regions of the gel containing ${ }^{35} \mathrm{~S}$.

The subcellular fractions, myelin and microsomes were also incubated with $\mathrm{Na}_{2}{ }^{35} \mathrm{SO}_{4}$ under identical conditions with those used for the synaptosomal fraction. After washing myelin and microsomal free of precursor and solubilization in sodium dodecyl sulphate/urea, samples were electrophoresed as before. In both instances no radioactivity was observed in any of the protein-staining bands or in the material applied to the gels.

After hydrolysis of the synaptic-plasmamembrane preparation with papain and removal of glycosaminoglycans, the soluble fraction was chromatographed on DEAE-cellulose. Over $90 \%$ of the radioactivity was resolved as a single band at $0.2 \mathrm{M}-\mathrm{NaCl}$ in the linear salt gradient. Further chromatography of this fraction on a Sephadex G-50 column resulted in the elution of a single low-molecular-weight species (Fig. 2). Chemical characterization revealed that the carbohydrate moiety accounted for $55 \%$ of the glycopeptide on a dry-weight basis. On analysis the sugar content was enriched with $N$-acetylglucosamine, mannose, galactose sialic acid and fucose $(0.68,0.6,0.37,0.33$ and $0.3 \mu \mathrm{mol} / \mathrm{mg}$ of glycopeptide respectively). No hexuronic acid was detected. Amino acid analysis 


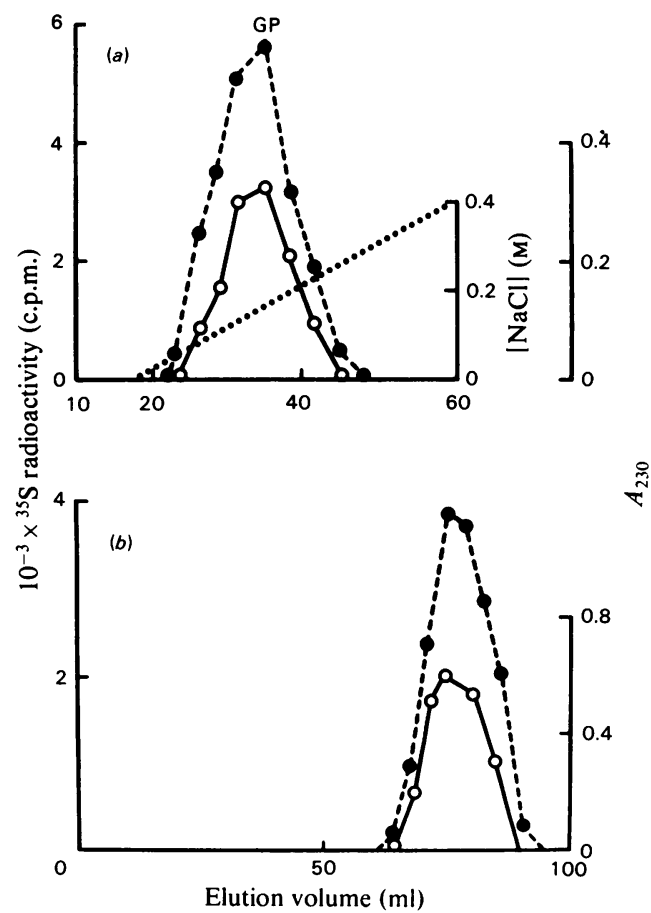

Fig. 2. DEAE-cellulose and gel filtration of papaintreated synaptic membranes

(a) Defatted membranes were treated with papain and chromatographed on a DE-52 column $(2.5 \mathrm{~cm} \times 20 \mathrm{~cm})$. The column was eluted with a linear $\mathrm{NaCl}$ gradient $(.$.$) and fractions (2 \mathrm{ml})$ were monitored for $A_{230}(O)$ and ${ }^{35} \mathrm{~S}(\boldsymbol{O})$. Abbreviation used: GP, glycopeptide. (b) Shows Sephadex G-50 chromatography of the ${ }^{35} \mathrm{~S}$-containing fraction isolated in $(a)$. The column $(1.5 \mathrm{~cm} \times 63 \mathrm{~cm})$ was eluted with $0.1 \mathrm{M}$-sodium phosphate and then $2 \mathrm{ml}$ fractions were collected and measured for $A_{230}(\mathrm{O})$ and ${ }^{35} \mathrm{~S}$ radioactivity $(\boldsymbol{O})$.

showed that the glycopeptide was rich in aspartate, glutamate, glycine, serine, threonine and alanine, which contributed $75 \%$ of the total amino acids present in the peptide moiety. No sulphur-containing amino acids were identified on analysis. Hydrolysis of the glycopeptides in $6 \mathrm{M}-\mathrm{HCl}$ followed by the addition of $\mathrm{BaCl}_{2}$ resulted in all the radioactivity being collected in the pellet isolated after centrifugation. This result implies, together with the amino acid data, that all the ${ }^{35} \mathrm{~S}$ is present as the inorganic sulphate anion.

\section{Discussion}

The results (Table 1) suggest that the synaptosomes and synaptic membranes isolated are sufficiently pure to exclude the likelihood that another subcellular component is solely contributing to the ${ }^{35} \mathrm{~S}$-labelled material detected in these preparations. After incubation of radioactive inorganic sulphate with synaptosomes, synapticplasma-membrane proteins were characterized by gel electrophoresis (Fig. 1). A broad distribution of polypeptides was revealed and this pattern of protein-staining bands appeared to be similar to the protein profiles exhibited by rat and mice synaptic plasma membranes isolated by using similar experimental procedures (Banker et al., 1972; Smith \& Loh, 1977). In a previous study a large number of sulphated glycoproteins in rat brain synaptic plasma membranes was observed after the administration of $\mathrm{Na}_{2}{ }^{35} \mathrm{SO}_{4}$ in vivo (Simpson et al., 1976). Unfortunately the number and the molecular weights of these glycoproteins were not given. It would seem from the staining and radioactivity patterns on polyacrylamide gels that the sulphated glycoprotein distributions are similar to the range of values reported in the present investigation. It is noteworthy that some of the labelled proteins detected had similar molecular weights to the sulphated glycoproteins that had previously been identified as being associated with the synaptosomal insoluble material (White, 1980). However, in the present study longer incubation periods were adopted.

To characterize the radioactively labelled material identified on polyacrylamide gels as sulphated glycoproteins and to distinguish these macromolecules from glycosaminoglycans that have been located in synaptosomes (White, 1979b) delipified membranes were proteolytically degraded. Chemical analysis revealed that the glycopeptide lacked hexuronic acid and showed a similar sugar composition to glycopeptides previously characterized from the synaptic region (Simpson et al., 1976; Krusius et al., 1978).

In conclusion, the results presented indicate that inorganic sulphate can be incorporated into glycoproteins associated with synaptic plasma membranes. Whether the sulphation process occurs at the membrane level or if the glycoprotein fractions are modified before being membrane-bound is still unclear. However, in a recent study the sulphation of a high-molecular-weight glycoprotein associated with membranes derived from whole brain has been demonstrated (Miller \& Waechter, 1979). In addition, preliminary studies in this laboratory have indicated that the intermediate 3 '-phosphoadenosine 5'-sulphatophosphate, which has previously been identified in the synaptosomal fraction (Cumar et al., 1968), is associated with the sulphation of glycoproteins as characterized here.

I thank Miss J. Dawson for her technical help and Mrs. B. Walker for the preparation of this manuscript. 


\section{References}

Banker, G., Grain, B. \& Cotman, C. W. (1972) Brain Res. 42, 503-509

Brunngraber, E. G., Hof, H., Susz, J., Brown, B. D., Aro, A. \& Chang, I. (1973) Biochim. Biophys. Acta 304, 781-796

Cotman, C. W. \& Matthews, D. A. (1971) Biochim. Biophys. Acta 249, 380-394

Cumar, F. A., Barra, H. S., Maccioni, J. J. \& Caputo, R. (1968) J. Biol. Chem. 243, 3807-3816

Earl, D. C. N. \& Korner, A. (1965) Biochem. J. 94, 721-733

Ellman, G. L., Courtney, K. D., Andres, V. \& Featherstone, R. M. (1961) Biochem. Pharmacol. 7, 88-95

Fleck, A. \& Begg, A. (1965) Biochim. Biophys. Acta 108, 333-339

Groome, N. P. (1980) J. Neurochem. 35, 1409-1417

Gurd, J. W., Jones, L. R., Mahler, H. R. \& Moore, W. J. (1974) J. Neurochem. 22, 281-290

Johnson, M. K. (1960) Biochem. J. 77, 610-618

Jourdian, G. W., Dean, L. \& Roseman, S. (1970) J. Biol. Chem. 246, 430-435

Katzman, R. L. (1972) J. Biol. Chem. 247, 3744-3749

Krusius, T., Finne, J., Margolis, R. V. \& Margolis, R. K. (1978) Biochemistry 17, 3849-3854
Margolis, R. K., Crockett, C P., Kiang, W. L. \& Margolis, R. V. (1976) Biochim. Biophys. Acta 451, 465-469

Markwell, M. A. K., Haas, S. M., Breber, L. L. \& Tolbert, N. E. (1978) Anal. Biochem. 87, 206-210

Mattieu, J. M., Quarles, R. H., Podulso, J. F. \& Brady, R. O. (1975a) Biochim. Biophys. Acta 392, 159-166

Mattieu, J. M., Everly, J. L., Brady, R. O. \& Quarles, R. H. (1975b) Biochim. Biophys. Acta 392, 167-174

Miller, R. R. \& Waechter, C. J. (1979) Arch. Biochem. Biophys. 198, 31-41

Norton, W. T. \& Poduslo, S. E. (1973) J. Neurochem. 21, 749-757

Peters, T. J., Jenkins, W. \& Dubowitz, V. (1980) Clin. Sci. 59, 7-12

Simpson, D. L., Thorne, D. R. \& Loh, H. H. (1976) Biochemistry 15, 5449-5457

Smith, A. P. \& Loh, H. H. (1977) J. Neurochem. 28, 887-891

Verity, M. A. (1972) J. Neurochèm. 19, 1305-1317

White, C. J. B. (1978) Experientia 34, 1036-1038

White, C. J. B. (1979a) Z. Naturforsch. Teil C 34, 487-489

White, C. J. B. (1979b) J. Neurol. Sci. 41, 261-269

White, C. J. B. (1980) Neurosci. Lett. 16, 307-311 